Journal of Educational Research in Developing Areas (JEREDA)

Vol. 2. Issue 1, Pp. 52-62, 2021

http://www.jeredajournal.com

E-mail: info@jeredajournal.com

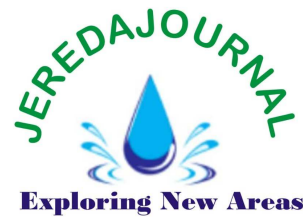

Research Article DOI: https://doi.org/10.47434/JEREDA.

eISSN : $2735-9107$

\title{
SELF-ESTEEM, FAMILY CONNECTEDNESS AND SOCIAL SKILLS ON ACADEMIC PERFORMANCE OF STUDENTS WITH HEARING IMPAIRMENT IN IBADAN, NIGERIA $*^{1}$ Emmanuel Olutunji Ajayi, ${ }^{2}$ Friday Ovie Azanor
}

\author{
${ }^{1,2}$ Federal College of Education (Special), Oyo, Nigeria \\ 1emolajay@gmail.com; ${ }^{2}$ fridayovia@yahoo.com \\ *Corresponding author: ${ }^{1}$ emolajay@gmail.com \\ (1) https://orcid.org/0000-0002-3854-7752
}

Received: $2^{\text {nd }}$ April, 2021; Revised:20 ${ }^{\text {th }}$ April, 2021; Accepted: $2^{\text {nd }}$ May, 2021

Abstract

ABSTRACT

Introduction: Extant and indigenous literature have shown that students with hearing impairment are found to be below their hearing counterparts in the area of academic and their poor academic performance most times is traced to lack of communication paying little or no attention to other factors.

Purpose: This study, therefore investigated factors such as self-esteem, family connectedness and social skills as determinants of on academic performance of students with hearing impairment in Ibadan Oyo State.

Design: Descriptive survey research designed was adopted in the study. A total of fifty two students with hearing impairment were selected through simple random sampling technique for the study. Purposive sampling technique was used to select three integrated schools in Ibadan. Four instruments were validated and used to collect relevant data. Three research questions were raised to guide the study. Data collected were subjected to a descriptive and inferential statistics.

Results: The study found that there was positive multiple correlation $(R=0.572)$ among self-esteem, social skills deficits and family connectedness on academic performance. All these factors in this order of magnitude: family connectedness $(r=$ $0.426, p<0.05)$; self-esteem $(r=0.419, p<0.05)$, and social skills deficits $(r=0.138$, $p<0.05$ ) predicted academic performance of students with hearing impairment.

Recommendations: It was therefore recommended that school counselors should provide direct service to parents, classroom teachers, school community and students with hearing impairment on the roles these factors play on the academic performance of students with hearing impairment.

Keywords: Hearing impairment, academic performance, self-esteem, social skills deficits, family connectedness

Cite paper as:

Crossref Ajayi, E. O., \& Azanor, F. O. (2021). Self-esteem, family connectedness Cited-by and social skills on academic performance of students with hearing impairment in Ibadan, Nigeria. Journal of Educational Research in Developing Areas, 2 (1), 52-62. https://doi.org/10.47434/JEREDA.2.1.2021.52.

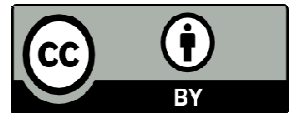

Copyright (c) 2021 The author(s) of this article retain(s) the copyright. 


\section{PUBLIC INTEREST STATEMENT}

The data gathered from this study would serve as baseline to interpret how selfesteem, family connectedness, and social skills serve as correlate of academic performance of secondary school students with hearing impairment. The finding of the study would provide the parents of students with hearing impairment with adequate information that would facilitate a better understanding on the academic performance of their wards with hearing impairment and how to handle it. The finding of the study would expose teachers of students with hearing impairment to how the factors considered herein contribute to the poor academic performance of students with hearing impairment. This work would ginger policy makers to organize in-service training in form of workshops, seminars, conferences, symposium, for teachers of students with hearing impairment, parents and curriculum planners. It would also serve as an additional practical knowledge for professionals such as social workers and educators. The results of the study would be useful to curriculum planners in that it would provide them with sound basis for factors affecting the academic performance of students with hearing impairment. The study has provided data that would add to the body of knowledge already in existence about issues affecting academic performance of students with hearing impairment. The study has provided additional empirical evidence on the impact of self-esteem, family connectedness and social skills on the academic performance of students with hearing impairment in secondary schools in Oyo state.

\section{INTRODUCTION}

Hearing is one of the main and most vital sensory organs that enables human being to adapt and adjust in their environment. Through this organ, man perceives, learn from and reacts to all that goes on in his immediate environment. When the hearing organ is impaired or reduced in function, the loss affects all areas of life including learning. Research has shown that the academic performance of students with hearing impairment is often the result of a complex interplay of many factors. When a person is unable to hear sound, significant language and psycho-social problems may develop because the sense of hearing provides a platform and gives feeling of security and participation in life. Due to their condition, many learners with hearing impairment find it difficult to establish a relationship, express themselves, and relate with their peers, especially in the school setting. The inability to do these usually leads to low self-esteem which rubs on their academic performance. Researchers have found out in their studies that environment have significant effect on students' academic performance, however, most students are constantly faced with these factors being uninformed and unprepared to meet with these challenges with the resultant effect of poor academic performance. Academic performance has been considered by Sujata and Satapathy (2011) as an interactive function of many variables such as, stress, low selfesteem, social-emotional adjustment, anxiety, depression, loneliness, aggression, social skills deficits, fear, anger, stress, inferiority, family influence, family type, family connectedness, socioeconomic status of the parents, parental involvement, age and gender, family type, family connectedness.

Students with special needs are susceptible to low self-confidence, loss of self-esteem, high frustration level, anxiety, depression and despair. Selfesteem correlates with both temperament and behaviour while self consciousness, shyness e.g feelings of discomfort in social situations stems from negative self-views based on fear of disapproval by the society Lazarus (2014). The society often regards good academic performance as evidence of scholarly achievement; children with hearing impairment therefore find it difficult to measure up to this societal standard. Using the Asia experience as yardstick, Sujata and Satapathy (2011), opined that the academic performance of the students, (students with hearing impairment inclusive) go a long way in determining the interactive function of 
many psycho-social and demographic variables.

The findings of Moges (2006) on the consequence of deafness on the selfesteem, family connectedness and social skills and academic development of the students with hearing impairment disclosed that students with hearing impairment experienced social and emotional problems in different social contexts. Social skills are learned while in the social contexts in which individual are situated. However, for persons with hearing impairment there is a great difficulty in identifying components of interaction and social performance of other people as these involves verbal and non-verbal linguistic components of social competence. Fava de Quevedo and Andretta, (2020) found deficits in the social skills of the deaf children and adolescents with deafness. They stated that deafness results in difficulties in identifying elements of social performance in other people. The problems were brought about as a result of their failure to understand the basic concepts of language units such as words, phrases, and sentences either in communication or written forms. Disabling hearing loss refers to hearing loss greater them $40 \mathrm{~dB}$ in the better hearing ear. According to WHO (2018) 466 million people worldwide have disabling hearing loss. Out of which 432 million are adults and 34 million are children. This condition therefore qualifies them to receive special education services. Consequently, the extent of hearing loss in an individual learner would to some extent interfere with his or her school performances (Ademokoya, 1995).

Study by Patil and Pujar (2019) show that hearing impairment learner were significantly low on performance $(49.40 \%)$, social $(61 \%)$ and appearance $(71.40 \%)$ dimensions of self-esteem than hearing peers. Ademokoya, (2016) pointed out that the spoken language difficulties experienced by students with hearing impairment erode their selfesteem, destroy their achievement motivation and ultimately limit their academic achievement. Less understanding of what is going on and how others react to their behavior result in less accurate self images, and possibly low self-esteem for learners with hearing impairment. Study by Bat Chava, (2003) discovered lower self-esteem among persons with hearing impairment than among hearing ones. According to Marschark (2007), there is considerable research evidence that children with hearing impairment typically enter school impoverish social skills and social experiences when compare to their hearing peers.

Researches show that family connectedness has a positive influence on the academic performance of students generally. With parental support, communication, and interaction between/ among siblings of students with hearing impairment, these learners have an increased opportunity for better academic performance. Dore-Frances, (2017) maintained that academically successful children tend to come from families that are clearly organized and in which role relationship of family members are appropriate which usually shows in all areas of life including academic. In his study, Liu and Xie (2015) found that family relationship was greatly associated with academic performance of deaf students. Study by Akellet and Bangarana, (2019), shows no significant association between family connectedness and academic performance of deaf students. From the foregoing, the researcher is interested in finding out how low self-esteem, social skills deficits, family connectedness and would have direct impact on the academic performance of students with hearing impairment.

\section{STATEMENT OF THE PROBLEM}

Self-esteem,family connectedness social skills and academic performance of learners with hearing impairment have generally for many centuries engaged the attention of scholars in sociologists, psychologists, special educators, guidance counselors and social workers. Poor academic performance of students with hearing impairment most times is traced to lack of communication paying 
little or no attention to other factors which are psychological or social in nature. Parents, teachers, and school personnel hardly consider these factors as predictors of academic performance. Some of the consequences of these problems on these unique learners are; frustration, suspension, drop-out, expulsion, early pregnancy among others. This study therefore, was designed to examine factors such as low self esteem, and social skills deficits, family connectedness) as correlates of academic performance of some students with hearing impairment in Ibadan Metropolis Oyo State.

\section{PURPOSE OF THE STUDY}

Specifically, the study:

1. examined some psycho-social factors (low self esteem, social skills deficits and family connectedness) affecting the academic performance of some students with hearing impaired.

2. examined which among the variables will impact most on the academic performance of some students with hearing impairment.

3. verified whether both the psychological (low self esteem) and social (social skills deficits and family connectedness) variables when combined together will affect academic performance of some students with hearing impairment.

\section{RESEARCH QUESTIONS}

1. What are the relationships among the independent variables (selfesteem, social skills deficits and family connectedness) and academic performance of students with hearing impairment?

2. What is the joint effect of selfesteem, social skills deficits and family connectedness on the academic performance of students with hearing impairment?

3. What are the relative effects of self-esteem, social skills deficits and family connectedness on academic performance of students with hearing impairment?

\section{METHODOLOGY Research Design}

A descriptive survey research design was adopted in this study. It is an expo facto research because the study presents a description of event as they are. Therefore, no need to manipulate any of the variables. The survey research design also facilitates the collection of factual information about research problem.

\section{Population and Sample}

The target populations of this study are male and female students with hearing impairment in selected secondary schools for students with hearing impairment in Ibadan Metropolis Oyo State.

The sample for the study comprised 52 students with hearing impairment in JSS2. A purposive sampling technique was used to select three integrated schools in two Local Government Areas (Ibadan South-west and Ibadan North). A school in Ibadan South-west local government area (20 Methodist Grammar School, Ibadan), two (2) schools in Ibadan North local government area (20 Andrew Foster Memorial College), and (12 Ijokodo High School, Sango, Polytechnic Road, Ibadan). While simple random sampling technique was used in selecting 20 participants in Methodist Grammar School, Ibadan, 20 Andrew Foster Memorial College, and 12 Ijokodo High School, Sango, Polytechnic Road, Ibadan.

\section{Instruments for Data Collection}

The following instruments were used in the study:

1. Demographics Survey

2. Social Skills Rating System, (SSRS) Gresham \& Elliott 1990.

3. Rosenberg self-esteem scale

4. Index of Family Relations (IFR).

\section{Description of Instruments}

Demographics Survey

This measure was created specifically for the present study. The purpose of this survey was to record students' identifiers (i.e. sex, age, etcetera), and family structure. 


\section{Social Skills Rating System-Student}

The Social Skills Rating SystemStudent (Gresham \& Elliott, 1990), a secondary level student version, was used to obtain self-report social skill measures from students on four subscales, i.e., cooperation, assertion, self-control, empathy, which combines to yield a total social skill score from 20 items. Generally, the Social Skills Rating System (SSRS) instrument is used to collect data on the social Skills of participants. Social skill scores can range from 0 to 78. Internal consistency and test-retest reliability coefficients for scores was obtained from the SSRS. A higher score reflects above average social skills, while a lower score indicates below average social skills. Using the Cronbach Alph the reliability of social skills scalestudent was determined and it was therefore found to be reliable at 0.78

\section{Rosenberg self-esteem scale}

The Rosenberg self-esteem scale developed by Morris Rosenberg in (1965) was used to assess the self-esteem of the respondents. It is one of the most widely used self-esteem tests among psychologists and sociologists. The scale is ten Likert scale with items answered on a four-point scale from strongly agree to strongly disagree. Using the Cronbach Alpha the reliability of self-esteem scale was determined and it was therefore found to be reliable at 0.76

\section{Index of Family Relations (IFR)}

This measure is a 25 -item scale designed to measure the magnitude of family relationship problems (Hudson, 1992). Each of these items was rated on a 7-point Likert scale ranging from 1 (none of the time) to 7 (all of the time). Using the Cronbach Alpha the reliability of IFR was determined and it was therefore found to be reliable at 0.72

\section{Procedure for Data Collection}

Preliminary visits were made to the three selected schools for the study. The purpose of the visits was to acquainted the researcher with the schools and get some of the class teachers who served as the research assistants informed about the purpose of the study. The research assistances were adequately informed and trained about what the study entails and how it was to be carried out. The researcher established rapport with the students with hearing impairment used as participants and informed them on the significance of the study. Questionnaire was administered by the researcher with the aid of some research assistance. The researcher and his assistance asked the participants to answer the questions contained in the instrument faithfully. The participants were instructed to feel free to answer the questions and were assured that their responses were for research purpose only.

\section{Method of Data Analysis}

Data analysis, both descriptive statistics (frequency count and percentage) and inferential statistics was used to test the relative influence of the variables. Specifically, descriptive statistics was used to explain respondents socio demographic while Pearson Product Moment Correlation Coefficient was used to test the relationship between the variables. Multiple Regression Analysis was employed to analyze composite influence of independent Variables.

\section{RESULTS}

Research Question 1: What are the relationships among the independent variables (self-esteem, social skills deficits, family connectedness) and academic performance? 
Journal of Educational Research in Developing Areas (JEREDA)

Vol. 2. Issue 1, Pp. 52-62, 2021

http://www.jeredajournal.com

E-mail: info@jeredajournal.com

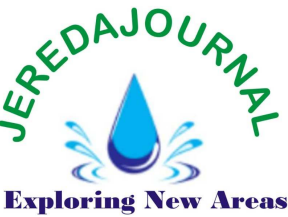

Table 1: Descriptive Statistics and Correlations among the Variables

\begin{tabular}{|c|c|c|c|c|c|c|c|c|}
\hline & 1 & 2 & 3 & 4 & 5 & 6 & 7 & 8 \\
\hline \multicolumn{9}{|l|}{ Family } \\
\hline Con & -0.076 & 1.000 & & & & & & \\
\hline Self-est. & $-0.149 *$ & $0.430 * *$ & $0.373 * *$ & $0.395 * *$ & 1.000 & & & \\
\hline $\begin{array}{l}\text { Soc. skills } \\
\text { deficits }\end{array}$ & $0.019 * *$ & 0.007 & 0.025 & 0.068 & -0.082 & 1.000 & & \\
\hline \multicolumn{9}{|l|}{ Academic } \\
\hline Perform. & -0.034 & $0.426 * *$ & $0.365^{* *}$ & $0.376 * *$ & $0.419 * *$ & $0.138^{*}$ & $0.138^{*}$ & 1.00 \\
\hline Mean & - & - & 23.25 & 23.72 & 24.29 & 13.468 & 21.94 & 21.51 \\
\hline \multicolumn{9}{|l|}{ Standard } \\
\hline Deviation & - & - & 5.038 & 5.188 & 6.457 & 0.604 & 4.799 & 5.710 \\
\hline
\end{tabular}

Table 1 shows means, standard deviation and zero order correlation among the variables. It was observed that there was significant relationship between the independent variables and the dependent variable (academic performance) in the following order of magnitude: family connectedness $(r=$ $0.426, p<0.05)$; self-esteem $(r=0.419$, $p<0.05)$, and social skills deficits $(r=$ $0.138, \mathrm{p}<0.05)$ in that order.

Research Question 2: What is the joint effect of self-esteem, social skills deficits, and family connectedness on the dependent variable: academic performance?

Table 2: Summary of Regression Showing Effects of Independent Variables on dependent variable (Academic Performance)

\begin{tabular}{cccc}
\hline R & R Square & Adjusted R Square & Standard Error Estimate \\
\hline 0.572 & 0.327 & 0.307 & 4.752 \\
\hline
\end{tabular}

From 2, it could be observed that there is positive multiple correlation $(R=$ 0.572 ) among the independent variables (self-esteem, social skills deficits, and family connectedness) on the dependent variable (Academic performance). This implies that these factors are relevant towards the determination of the dependent measure. The adjusted R- square value of 0.327 revealed that the independent variables accounted for $32.7 \%$ of the total variance in the dependent measure (Academic performance). The remaining $67.3 \%$ could be due to errors and factors that are not considered in this study. 
Journal of Educational Research in Developing Areas (JEREDA)

Vol. 2. Issue 1, Pp. 52-62, 2021

http://www.jeredajournal.com

E-mail: info@jeredajournal.com

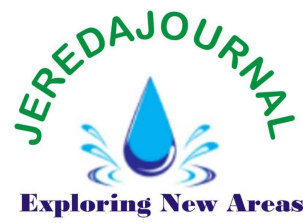

Table 3: Multiple Regression Showing Effect of Independent Variables on Academic Performance

\begin{tabular}{lcccccc}
\hline & $\begin{array}{l}\text { Sum of } \\
\text { Square }\end{array}$ & df & $\begin{array}{c}\text { Mean } \\
\text { Square }\end{array}$ & F & P & Remarks \\
\hline Regression & 2584.185 & 8 & 323.023 & 2.922 & 0.000 & Sig \\
Error & 5306.556 & 48 & 110.553 & & &
\end{tabular}

Total $\quad 7890.741 \quad 56$

Table 3 shows that the $\mathrm{R}$-value 0.572 tested significant $(F(7 / 48)=$ 2.922). Hence, self-esteem, social skills deficits, and family connectedness have significant predictable joint effect on academic performance.
Research Question 3: What are the relative effects of self-esteem, social skills deficits, and family connectedness on academic performance?

Table 4: Estimates of Relative Contribution of Independent Variables on the Academic performance of students with hearing impairment.

\begin{tabular}{|c|c|c|c|c|c|c|c|}
\hline & \multicolumn{2}{|c|}{$\begin{array}{l}\text { Unstandardized } \\
\text { Coefficient }\end{array}$} & \multirow{2}{*}{$\begin{array}{c}\text { Standardized } \\
\text { Coefficient }\end{array}$} & \multirow[t]{2}{*}{ Rank } & \multirow[t]{2}{*}{$\mathbf{T}$} & \multirow[t]{2}{*}{$\mathbf{P}$} & \multirow[t]{2}{*}{ Remark } \\
\hline & $B$ & Std. & & & & & \\
\hline Constant & -1.313 & 2.483 & - & & 0.529 & 0.598 & NSig \\
\hline \multicolumn{8}{|l|}{ Family } \\
\hline Connect & 0.249 & 0.077 & 0.210 & $2^{\text {nd }}$ & 3.232 & 0.001 & Sig \\
\hline Self-est. & 0.196 & 0.056 & 0.221 & $1^{\text {st }}$ & 3.463 & 0.001 & Sig \\
\hline \multicolumn{8}{|c|}{ Social skills } \\
\hline Deficits & 1.663 & 0.512 & 0.176 & $3^{\text {rd }}$ & 3.252 & 0.001 & Sig \\
\hline
\end{tabular}

From the table 4 above, self-esteem made the highest contribution to academic performance $(\beta=0.221, \mathrm{t}=$ $3.463, p<0.05)$ followed by family connectedness $(\beta=0.210, t<0.05)$, followed by social skill deficits $(\beta=$ $0.176, t=3.252, p<0.05)$.

\section{DISCUSSIONS}

The discussion of findings is presented in consonance with variables contained in the research questions examined in this study:

Research Question 1: Would there be significant relationships among the independent variables (self-esteem, social skills deficits, and family connectedness) on academic performance?

Using means, standard deviation and zero order correlation among the variables, it was observed that there was significant relationship among some of the independent variables (self-esteem, 
social skills deficits, and family connectedness) and the dependent variable (academic performance) in the following order of magnitude: family connectedness; self-esteem, and social skills deficits respectively no significant relationship with academic performance of students with hearing impairment. This finding is in line with the finding by Patil and Pujar (2019) who found that hearing impairment learner were significantly low on performance $(49.40 \%)$, social $(61 \%)$ and appearance $(71.40 \%)$ dimensions of self-esteem than hearing peers. Ademokoya, (2016) also pointed out that the spoken language difficulties experienced by students with hearing impairment erode their self-esteem, destroy their achievement motivation and ultimately limit their academic achievement. The finding is also in consonant with that of Liu (2013) which shows that family relationship was greatly associated with academic performance of deaf students. The finding of this study is not in line with that of Akellet and Bangarana, (2019) who found no significant association between family connectedness and academic performance of deaf students.

Research Question 2: What is the joint effect of self-esteem, social skills deficits, and family connectedness on the dependent variable: academic performance?

Research question one indicated that the independent variables (selfesteem, social skills deficits, and family connectedness) have a joint effect on dependent variable (academic performance). This implies that independent variables accounted for $32.7 \%$ of the total variance in the dependent variable (Academic performance). This finding agrees with Sujata and Satapathy (2011) who found that academic performance has been considered by as an interactive function of many variables such as, stress, low self-esteem, social-emotional adjustment, anxiety, depression, loneliness, aggression, social skills deficits, fear, anger, inferiority, family influence, family type, family connectedness, socio-economic status of the parents, parental involvement, age and gender among others. Also, DoreFrances, (2017) maintained that academically successful children tend to come from families that are clearly organized and in which role relationship of family members are appropriate which usually shows in all areas of life including academic.

Research Question 3: What are the relative effects of self-esteem, social skills deficits, and family connectedness on academic performance?

The main criterion variable in this study is academic performance. All the independent variables were found to contribute differently to academic performance of students with hearing impairment. These independent variables, which are (family connectedness $(r=0.426, p<0.05)$; self-esteem $(r=0.419, p<0.05)$, and social skills deficits $(r=0.138, p<0.05)$ in that or, ) were significantly correlated with the dependent variable. All of these variables were positively correlated with dependent variable (academic performance). Beta weight rank shows the order of magnitude of effect of independent variables on dependent variable. family connectedness made the highest contribution to academic performance (ranked $1^{\text {st }}$ ), followed by self-esteem (ranked $2^{\text {nd }}$ ), followed by social skill deficits (ranked $3^{\text {rd }}$ ). Family connectedness had the highest impact on academic performance of students with hearing impairment in this study. Family connectedness is a positive significant contributor for classroom behavior of students with hearing impairment. Research scholars corroborate the findings of this study. The finding by Moges (2006) on the consequence of deafness on the self-esteem, family connectedness and social skills and academic development of the students with hearing impairment disclosed that students with hearing impairment experienced social and emotional problems in different social contexts. Social skills deficit ranked third among the psychosocial variables that affect 
academic performance of students with hearing impairment. High to moderate academic performance is often regarded as evidence of scholarly achievement. Many scholars reported that social skills deficit is one of the psychological factors that children with hearing impairment experienced. Social skills play a critical role in a child's all round development. Andretta, (2020) found deficits in the social skills of the deaf children and adolescents with deafness. They stated that deafness results in difficulties in identifying elements of social performance in other people. Anderson, Olsson, Rydell, and Larsen, (2000) stated that refusal to address the social skills needs of children with or without special needs can lead to academic skill deficits as well as the need for therapeutic and psychosocial treatment. Self-esteem came second in the degree of magnitude where the academic performance of students with hearing impairment is concerned. Children with hearing impairment experience low self-esteem because they have a basis for academic comparison. These students have feelings of low self-esteem because they lag behind academically when compared to their hearing counterparts. Study by Bat Chava, (2003) discovered lower selfesteem among persons with hearing impairment than among hearing ones.

\section{CONCLUSION}

This study examined self-esteem, family connectedness and social skills as correlate of academic performance of students with hearing impairment. It was found that all the independent variables were correlated to academic performance of students with hearing impairment. Therefore, in colleting information on the academic performance of students with hearing impairment their self-esteem, social skills and family connectedness should be considered

\section{EDUCATIONAL IMPLICATIONS}

The results obtained in this study have demonstrated that self-esteem, social skills deficits, and family connectedness have effect on academic performance of students with hearing impairment. The implication is that teachers of students with hearing impairment need to pay extraordinary attention to the psycho- social problems of these students. If these independent variables are not put into proper consideration these students might find academic work cumbersome and this might lead to frustration, suspension, school drop-out, expulsion and teenage early pregnancy.

The finding also revealed that lack of communication between students with hearing impairments and the society is the major barrier for high social skills. Therefore, parents, family members and the society at large should try as much as possible to learn the medium of communicating with persons with hearing impairment by learning one or two aspects of total communication (especially sign language) if not all. Regular counseling for these students would teach them how to cope with their psycho-social problems and poor academic performance. This would encourage them to realize that with basic education and determination they can forge ahead and make good success in any vocational endeavour they wish to engage in. For teachers and parents of these students regular counseling would ensure a better understanding of how to relate with them.

\section{RECOMMENDATIONS}

On the basis of the discussion of results and general experience in the course of the study, the following recommendations are considered necessary:

1. Schools counselors should provide direct services to parents, students with hearing impairment, classroom teachers, school community on the roles these independent variables play on the academic performance of children with hearing impairment.

2. Special educators should employ teaching strategies which would help the students with hearing impairment to structure their own knowledge and reveal their innate abilities. 
3. Parents of students with hearing impairment should play a role in the promotion of their children's academic performance for successful independence life.

4. Schools for persons with special needs should also organize talk on academic performance inviting prominent persons with special needs (especially hearing impaired) and without special needs to talk and challenge the students about their academic performance among other things.

5. The federal and state Government should endeavour to equip all integrated schools for students with hearing impairment with qualified special teachers in various academic disciplines. So that these students would have the opportunities of choosing from different various academic subjects instead of being streamlined into a particular subjects.

Conflicts of Interest: The authors declare no conflict of interest.

Disclaimer Statement: This work is not an extraction of any work.

\section{Notes on Authors}

Emmanuel Olutunji Ajayi is a lecturer in the Department of Rehabilitation Education at the Federal College of Education (Special), Oyo, Oyo State, Nigeria. His research interests are deaf education, sexuality and sexual behaviour and rehabilitation of the hearing impaired. $\mathrm{He}$ is presently studying for the award of Degree of Doctor of Philosophy in the Department of Special Education, Faculty of Education, University of Ibadan, Ibadan, Nigeria. He is a member of Teacher Registration Council of Nigeria, Nigeria Association of Special Education Teachers, National Association for Exceptional Children, Educational Sign Language Interpreter Association of Nigeria.

Friday Ovie Azanor is a lecturer in the Department of Education for Learners with Communication and Behaviour Disorders at the Federal College of Education (Special), Oyo, Oyo State, Nigeria. His research interests are deaf education, communication disorders, deafblindness, behaviour disorders and training of adolescents with hearing impairment on life skills. He is presently studying for the award of Degree of Doctor of Philosophy in the Department of Special Education, Faculty of Education, University of Ibadan, Ibadan, Nigeria. He is a member of Teacher Registration Council of Nigeria, Nigeria Association of Special Education Teachers, National Association for Exceptional Children, Educational Sign Language Interpreter Association of Nigeria.

\section{Authorship and level of contribution}

Both authors gathered data for the study. While FOA prepared the manuscript and subjected the manuscript to plagiarism test, EOA validated the instruments, analysed and interpreted the data. FOA proofread the manuscript. Both authors perused and approved the final manuscript for submission.

\section{References}

Ademokoya, J. A. (1995). Effects of direct and indirect strategies on reasoning skills in some seccondary school hearing-impaired students. An unpublished Ph.D Thesis. Department of Special Education, University of Ibadan.

Akellet, J., \& Bangarana, P. (2019). Association between parental involvement and academic achievement of of deaf children at Mulago deaf school Kampala, Uganda. Afri Health Science 19(2), 2270-2281.

Anderson, G,. Olsson, E., Rydell, A.M., and Larsen, H. C. 2000. Social competence and Behavioural problems in children with hearing impairment. Audiology 39,88-92

Bat-Chava, Y., \& Martin, D. (2003). Negotiating deaf-hearing friendships: Coping strategies of 
deaf boys and girls in mainstream schools. League for the Hard of Hearing, 511-519.

Dore-Frances, M. A. (2017). Family emotional connectedness. www.teensconnecting.com.

Gresham, F. M., and Elliott, S. N. (1990). Social skills rating system. Circle Pines, MN: American Guidance Service.

Fava de Quevedo, R., \& Andretta, I. (2020). Social skills in children and adolescents: Differences between deaf and hearing. Journal of Developmental Psychology, 30 (1), 112-120.

Lazarus, P. J. (2014). Correlations of shyness and self-esteem for elementary school children. Perception and Motro, 5, 8-10.

Liu, C. (2013). Academic and social adjustment among deaf and hard of hearing college students in Taiwan. A Ph.D Thesis. Department of Special Education, University of Kansas.

Marschark, M. (2007). Raising and educating a deaf child: $A$ comprehensive guide to the choices, controversies, and decisions faced by parents and educators. (2nd ed.). Oxford University Press.

Moges, A. (2006). The consequence of deafness on the psychological development of deaf students with reference to Alpha special school for deaf Addis Ababa. Ethiopia Journal of Education and Science 1(2) 6188

Patil, S., \& Pujar, L. (2019). Differential Effects of hearing status on selfesteem among school children. International Journal of Current Microbiology and Applied Sciences 8 (9), 1825-1833.

Sujata, S., \& Satapathy, N. (2011). Psychosocial \& demographic correlates of academic performance of hearing impaired adolescent. Japan. Asia Pacific Disability Rehabilitation. Journal 19(2), 1925.

WHO. (2018). hearing day/World-Hearing Day-Infographic- $\quad$ EN.pdf?ua $=1$ https://www.who.int/deafness/worl $\underline{\mathrm{d}}$ 